\title{
Biossegurança: perspectivas na área da saúde
}

\section{Gustavo Cardoso da Silva ${ }^{1}$, Gerson Tavares Pessoa ${ }^{1 *}$, Kamila Araújo de Mesquita ${ }^{2}$, Gerlan Vieira de Sousa ${ }^{1}$}

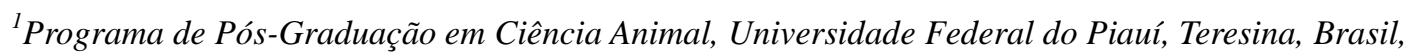

${ }^{2}$ Biomédica, Faculdade de Tecnologia de Teresina - CET, Teresina, Piauí, Brasil

"E-mail para correspondência-gersonpessoa@hotmail.com

RESUMO. Organização Mundial de Saúde conceituou a biossegurança como práticas de prevenção para o trabalho em laboratório com agentes patogênicos, e, além disto, classificaram os riscos como biológicos, químicos, físicos, radioativos e ergonômicos. Em decorrência disso, novos avanços e normalizações têm sido desenvolvidos para melhorar a vida das pessoas que trabalham com agentes de riscos na área da saúde. Desta forma, as ações propostas pela Biossegurança integram o conjunto de medidas preventivas que investigam, monitoram e propõem procedimentos de controle à disseminação dos agravos para atender às demandas de saúde publica. O objetivo desta revisão é fornecer conhecimentos da evolução na biossegurança através de informações recentes (1996 a 2014) sobre histórico, desenvolvimento e importância sobre a mesma, abrangendo os aspectos relevantes para maior compreensão dos cuidados dentro de um laboratório, com suas técnicas, cuidados e aspectos de controle para evitar acidentes.

Palavras-chave: laboratório, prevenção, riscos, segurança do ambiente

\section{Biosafety: perspectives in the área in health}

\begin{abstract}
World Health Organization conceptualized as biosecurity prevention practices for laboratory work with pathogens, and, moreover, rated the risks as biological, chemical, physical, ergonomic and radioactive. As a result, new developments and normalization have been developed to improve the lives of people who work with agents in health risks. Thus, the actions proposed by Biosecurity constitute the set of preventive measures that investigate, monitor and propose procedures to control the spread of infectious diseases to meet the demands of public health. The aim of this review is to provide knowledge of developments in biosafety information through recent (1996-2014) on history, development and importance on it, covering the relevant aspects for a better understanding of care within a laboratory, with its techniques, care and aspects of control to avoid accidents.
\end{abstract}

Keywords: laboratory, prevention, risk, environmental safety

\section{Introdução}

O conceito de biossegurança começou a ser construído no início da década de 1970, após o surgimento da engenharia genética. A transferência e expressão do gene da insulina para a bactéria Escherichia coli foi o primeiro procedimento que utilizou biotécnicas de engenharia genética. Esta pesquisa provocou o surgimento da Conferência de Asilomar, na Califórnia em 1974. Nesta foram debatidas questões sobre os riscos das técnicas de engenharia genética e segurança dos espaços laboratoriais (Albuquerque, 2001; Borém, 2001).
Na década de 1980, a Organização Mundial de Saúde conceituou biossegurança como práticas de prevenção para o trabalho em laboratório com agentes patogênicos, classificando os riscos como biológicos, químicos, físicos, radioativos e ergonômicos. $\mathrm{Na}$ década seguinte, observaram-se a inclusão de temas incipiente como ética em pesquisa, meio ambiente, animais e processos envolvendo tecnologia de DNA recombinante em programas de biossegurança (Costa \& Costa, 2002).

Em 1995, foi criada a Comissão Técnica Nacional de Biossegurança (CTNBio), com 
vistas a estabelecer normas às atividades que envolvam construção, cultivo, manipulação, uso, transporte, armazenamento, comercialização, consumo, liberação e descarte de "Organismos Geneticamente Modificados" (OGMs) em todo o território brasileiro (Scholze, 1999).

A preocupação com a saúde do trabalhador de uma maneira geral, em especial com trabalhadores da saúde, vem crescendo nos últimos anos. Em decorrência disso, novos avanços e normalizações têm sido desenvolvidos para melhorar a vida das pessoas que trabalham com agentes de riscos na área da saúde (Souza, 2002).

Assim, biossegurança é o conjunto de ações voltadas para a prevenção, minimização ou eliminação dos riscos inerentes às atividades de pesquisa, produção, ensino, desenvolvimento tecnológico e prestação de serviços. Estes riscos podem comprometer a saúde do homem e animais, o meio ambiente ou a qualidade dos trabalhos desenvolvidos (Teixeira \& Valle, 1996).

Biossegurança engloba a análise dos riscos a que os profissionais de saúde e de laboratórios estão constantemente expostos em suas atividades e ambientes de trabalho. A avaliação de tais riscos engloba vários aspectos, sejam relacionadas aos procedimentos adotados, as chamadas boas práticas em laboratório (BPLs), aos agentes biológicos manipulados, à infraestrutura dos laboratórios ou informacionais, como a qualificação das equipes (Brasil, 2006b).

Para educar e promover a consciência em biossegurança, membros selecionados da CTNBio visitam instituições públicas e privadas periodicamente. Durante essas visitas, os membros apresentam seminários e discutem, com a equipe técnica das instituições, artigos atuais em biossegurança, problemas relacionados à aplicação de guias e outros assuntos relevantes (CTNBio, 2006).

O objetivo desta revisão é fornecer conhecimentos da evolução na biossegurançacom informações recentes (1996 a 2014) sobre histórico, desenvolvimento e importância sobre a mesma, abrangendo os aspectos relevantes para maior compreensão dos cuidados dentro de um laboratório, com suas técnicas, cuidados e aspectos de controle para evitar acidentes.

\section{Revisão}

Desde o final século XX, a produção do conhecimento em todas as áreas passa por um processo de aceleração resultante da crescente unificação entre ciência, tecnologia, trabalho e cultura, criando novos objetos e campos do conhecimento científico. É nessa conjuntura que emerge o campo da Biossegurança, que procura discutir eticamente interfaces entre a adoção de processos laborais seguros e preocupações ambientais de caráter amplo, envolvendo diferentes aspectos relativos à segurança do ambiente e da saúde humana (Rocha, Bessa \& Almeida, 2012).

$\mathrm{O}$ conceito de biossegurança, do termo em inglês biosafety foi inicialmente aplicado para indicar um conjunto de ações necessárias à contenção de riscos inerentes a exposição ou liberação acidental de agentes infecciosos em laboratórios, tendo como preocupação central a construção de ambientes saudáveis. Avanços da ciência e da tecnologia trouxeram diferentes inquietudes, ampliando seu foco e campo de aplicação de modo a abranger a construção de sistemas de prevenção e controle para diferentes situações de risco (Navarron \& Cardoso; Cardoso, 2008).

O campo da biossegurança discute temas complexos que integram objetos tratados por diferentes áreas do conhecimento científico, como a ecologia, a epidemiologia, a biotecnologia, a bioética, a sociologia, dentre outras (Rocha, 2003).

Desta forma, as ações propostas pela Biossegurança integram o conjunto de medidas preventivas que investigam, monitoram e propõem procedimentos de controle à disseminação dos agravos para atender às demandas de saúde publica relativas à expansão das doenças emergentes e reemergentes, resultantes do acelerado processo predatório do ambiente. Essas reflexões demonstram a importância de inserir 
a discussão do tema nos mais diversos fóruns no contexto da saúde (Rocha, Bessa \& Almeida, 2012).

$\mathrm{O}$ aumento da preocupação quanto à biossegurança determina a importância da produção de estudos acerca dessa temática como alternativa (Teixeira \& Valle, 1996). A prevenção de riscos à saúde ambiental e humana é objetivo central da Biossegurança, a qual dialoga e se apropria de saberes imprescindíveis de outras áreas do conhecimento científico, o que caracteriza a interdisciplinaridade do campo. Esta propõe a avaliação de risco como primeiro passo para a elaboração de propostas preventivas, e como prática possibilitadora do desenvolvimento sustentável, constituindo uma estratégia capaz de promover interseções importantes entre os projetos científicos e industriais, as instituições e a sociedade, em todos os níveis de representação ou atuação, no sentido da preservação da vida no planeta (Rocha, Bessa \& Almeida, 2012).

O responsável pelo gerenciamento do laboratório, seja este de saúde ou outras áreas, deve oferecer a seus empregados a garantia de trabalhar com segurança, vacinação, reforçar as políticas de proteção e segurança, manter materiais perigosos em local seguro, entre outros aspectos que garantam a minimização de riscos (Sewell, 2006).

A execução da biossegurança muitas vezes se depara com resistências vinculadas a vários fatores, tais como carência de infraestrutura equipamentos sem manutenção, áreas laboratoriais em condições precárias de uso, faltam de insumos, insumos inadequados, entre outros, cristalização de mentalidades relativas à exposição ao risco levando a subestimação e negligência frente ao risco (Marziale\& Rodrigues, 2002).

Os equipamentos de proteção individual, conhecidos como EPIs, são utilizados para minimizar a exposição aos riscos ocupacionais e evitar possíveis acidentes no laboratório. Os equipamentos de proteção coletiva (EPCs) são utilizados com a finalidade de minimizar a exposição dos trabalhadores aos riscos e, em casos de acidentes, reduzir suas consequências. Exemplos: lava-olhos, chuveiro, extintor e cabines de proteção biológica (Teixeira \& Valle, 1996).

Os laboratórios são divididos respeitando os níveis de biossegurança (NB) em que se enquadram, denominados NB-1, NB-2, NB-3 e NB-4. Tais níveis estão relacionados aos requisitos crescentes de segurança para o manuseio dos agentes biológicos, terminando no maior grau de contenção e de complexidade do nível de proteção. O NB exigido para um ensaio será determinado pelo agente biológico de maior classe de risco envolvido no ensaio. Nível de biossegurança1 (NB-1): É o nível necessário ao trabalho que envolva agentes biológicos da classe de risco 1. Representa um nível básico de contenção, que se fundamenta na aplicação das BPLs, na utilização de equipamentos de proteção e na adequação das instalações. O trabalho é conduzido, em geral, em bancada. Nível de biossegurança2 (NB-2): É o nível exigido para o trabalho com agentes biológicos da classe de risco 2. O acesso ao laboratório deve ser restrito aos profissionais da área, mediante autorização do profissional responsável. Nível de Biossegurança3 (NB-3): Este nível é aplicável aos locais onde forem desenvolvidos trabalhos com agentes biológicos da classe de risco 3. Nível de biossegurança4 (NB-4): Este nível é necessário a trabalhos que envolvam agentes biológicos da classe de risco 4 e agentes biológicos especiais. Nesse tipo de laboratório o acesso dos profissionais deve ser controlado por sistema de segurança rigoroso (Brasil, 2006a).

Preocupações com aspectos ligados a biossegurança não são atuais. Historicamente, no antigo Egito, quando os faraós eram embalsamados, uma das inquietações residia em como manipular agentes químicos sem correr riscos de contaminação. Para resolver esta questão foram criados equipamentos de proteção individual para os manipuladores (Silva, Furtado \& Silva, 2007).

O maior problema relacionado aos riscos em laboratório não está nas tecnologias disponíveis para eliminar ou minimizar tais riscos e sim no comportamento dos 
profissionais. É indispensável relacionar o risco de acidentes às boas práticas cotidianas dentro de um laboratório. Não basta haver sistemas modernos de esterilização do ar ou câmaras de desinfecção das roupas de segurança, por exemplo, se o profissional não lavar suas mãos com a frequência adequada ou o lixo for descartado de maneira errada (ANVISA, 2005).

As Boas Práticas de Laboratório (BPLs) tratam da organização, do processo e das condições sob as quais estudos de laboratório são planejados, executados, monitorados, registrados e relatados. As BPLs têm como finalidade avaliar o potencial de riscos e toxicidade de produtos objetivando a proteção da saúde humana, animal e do meio ambiente. Outro objetivo das BPLs é promover a qualidade e validação dos resultados de pesquisa através de um sistema de qualidade aplicado a laboratórios que desenvolvem estudos e pesquisas que necessitam da concessão de registros para comercialização de seus produtos e monitoramento do meio ambiente e da saúde humana (EMBRAPA, 2014).

Muitas das reavaliações das estratégias educacionais, informacionais e mesmo as intervenções pertinentes a este campo envolvem elementos de subjetividade (Navarro \& Cardoso, 2009).

\section{Conclusões}

Estudos de revisão como estes fornecem informações importantes sobre a evolução, cuidados, boas práticas, técnicas e medidas que possibilitam uma maior segurança para diminuir ou mesmo eliminar os riscos, prevenindo contaminações durante realizações das atividades.

Em meio aos riscos, os artigos revisados demonstram que as ações educativas ampliam conhecimentos dos profissionais sobre técnicas e recomendações em relação às práticas de biossegurança.

\section{Referências Bibliográficas}

Agência Nacional de Vigilância Sanitária ANVISA. Biossegurança. Revista de Saúde Pública, v.39, n.6, p.989-991, 2005.

Albuquerque, M.B.M. Biossegurança, uma visão da história da ciência. Biotecnologia, Ciência \& Desenvolvimento, v.3, n.18, p.42-45, 2001.

Borém, A. Escape gênico \& transgênicos. Viçosa: Suprema, 2002.

Brasil. Ministério da Saúde. Classificação de risco dos Agentes Biológicos. Brasília: Editora MS, 2006a.

Brasil. Ministério da Saúde. Diretrizes gerais para o trabalho em contenção com Agentes Biológicos. Brasília: Editora MS, $2006 \mathrm{~b}$.

Cardoso, T.A.O. Análise da construção da competência do Brasil em direção ao Laboratório de Contenção Máxima: realidades e perspectivas. Tese de Doutorado. Escola Nacional de Saúde Pública Sérgio Arouca (ENSP), Rio de Janeiro (RJ), 2008.

Comissão Técnica Nacional de Biossegurança (Brasil). Relatório Anual da CTNBio 2006. Acesso em: 30 abr. 2014.

Costa, M.A.F.; Costa, M.F.B. Biossegurança: elo estratégico de SST. Centro Nacional de Epidemiologia/Fundação Nacional de Saúde/Ministério da Saúde, 2010-Setor de Autarquias Sul, Brasília DF Brasil. Revista CIPA, n.253, 2002.

EMBRAPA - Empresa Brasileira de Pesquisa Agropecuária. Boas práticas de laboratório. Acesso em: 6 mar. 2014

Marziale, M.H.P.; Rodrigues, C.M. A produção cientifica sobre acidentes de trabalho com material perfurocortante entre trabalhadores de Enfermagem. Revista Latino Americana de Enfermagem, v.10, n.4, p.571-577, 2002.

Navarro, M.B. \& Cardoso, T.A.O. Biossegurança e ambiente: complexidade e instrumentalização. Gaia Scientia, v.1, n.2, p.107-114, 2007. 
Navarro, M.B.M.A.; Cardoso, T.A.O. Biossegurança e a dimensão subjetiva do trabalho e do risco. Revista de Saúde Coletiva, v.19, n.4, p.941-952, 2009.

Rocha S.S.; Bessa T.C.B. \& Almeida A.M.P. Biossegurança, proteção ambiental e saúde: compondo o mosaico. Ciência \& Saúde Coletiva, v.17, n.2, p.287-292, 2012.

Rocha, S.S. Biossegurança, um novo desafio na formação do profissional de saúde pública: avaliação da implementação do programa nacional de Capacitação em Biossegurança Laboratorial na Bahia. Dissertação de Mestrado. Universidade Federal da Bahia (UFBA), Salvador, 2003.

Scholze, S.H. Biossegurança e alimentos transgênicos. Revista Biotecnologia, Ciência e Desenvolvimento, v.2, n.9, p.3234, 1999.

Sewell, D.L. Laboratory-acquired Infections: Are microbiologists at risk? Clinical Microbiology Newsletter, v.28, n.1, p.1-6, 2006.
Silva, R.M.G.; Furtado, S.T.F. \& Silva C.V. Biossegurança no laboratório de química: um estudo de caso. Biológico, v.69, n.1, p.23-30, 2007.

Souza, A.C.S. Risco biológico e biossegurança no cotidiano de enfermeiros e auxiliares de enfermagem. Revista Eletrônica de Enfermagem, v.4, n.1, p.65, 2002.

Teixeira, P.; Valle, S. (Ed.). Biossegurança: uma abordagem multidisciplinar. Rio de Janeiro: Fiocruz, 1996. p.163-189

\section{Recebido em Maio 27, 2014.}

Aceito em Julho 22, 2014.

License information: This is an open-access article distributed under the terms of the Creative Commons Attribution License, which permits unrestricted use, distribution, and reproduction in any medium, provided the original work is properly cited. 